\title{
Effect of Therapeutic Hypothermia Initiated After 6 Hours of Age on Death or Disability Among Newborns With Hypoxic-Ischemic Encephalopathy:
}

\section{A Randomized Clinical Trial}

\section{Abbot R. Laptook, MD,}

Department of Pediatrics, Women \& Infants Hospital, Brown University, Providence, Rhode Island

Seetha Shankaran, MD,

Department of Pediatrics, Wayne State University, Detroit, Michigan

Jon E. Tyson, MD, MPH,

Department of Pediatrics, McGovern Medical School at the University of Texas Health Science Center at Houston

Breda Munoz, PhD,

Social, Statistical, and Environmental Sciences Unit, RTI International, Research Triangle Park, North Carolina

Edward F. Bell, MD, Department of Pediatrics, University of lowa, lowa City

Ronald N. Goldberg, MD,

Department of Pediatrics, Duke University, Durham, North Carolina

Nehal A. Parikh, DO, MS,

Corresponding Author: Abbot R. Laptook, MD, Women \& Infants Hospital of Rhode Island, 101 Dudley St, Providence, RI 02905 (alaptook@wihri.org).

Author Contributions: Ms Munoz and Dr Pedroza had full access to all of the data in the study and take responsibility for the integrity of the data and the accuracy of the data analysis.

Concept and design: Laptook, Shankaran, Tyson, Bell, Parikh, Ambalavanan, Pedroza, Pappas, Das, Ehrenkranz, Hensman, Chalak, Frantz, Devaskar, Carlton, Sánchez, Higgins.

Acquisition, analysis, or interpretation of data: Laptook, Shankaran, Munoz, Bell, Goldberg, Parikh, Ambalavanan, Pedroza, Pappas, Das, Chaudhary, Ehrenkranz, Hensman, Van Meurs, Chalak, Hamrick, Sokol, Walsh, Poindexter, Faix, Watterberg, Frantz, Guillet, Devaskar, Truog, Chock, Wyckoff, McGowan, Harmon, Brumbaugh, Cotten, Sánchez, Hibbs, Higgins.

Drafting of the manuscript: Laptook, Tyson, Munoz, Ambalavanan, Pedroza, Sánchez.

Critical revision of the manuscript for important intellectual content: Laptook, Shankaran, Tyson, Bell, Goldberg, Parikh,

Ambalavanan, Pappas, Das, Chaudhary, Ehrenkranz, Hensman, Van Meurs, Chalak, Hamrick, Sokol, Walsh, Poindexter, Faix,

Watterberg, Frantz, Guillet, Devaskar, Truog, Chock, Wyckoff, McGowan, Carlton, Harmon, Brumbaugh, Cotten, Sánchez, Hibbs, Higgins.

Statistical analysis: Shankaran, Tyson, Munoz, Pedroza, Das.

Obtained funding: Shankaran, Bell, Ambalavanan, Hensman, Walsh, Faix, Frantz III, Truog, Carlton, Cotten, Sánchez.

Administrative, technical, or material support: Bell, Goldberg, Chaudhary, Hensman, Chalak, Hamrick, Faix, Devaskar, Chock, Wyckoff, McGowan, Carlton, Hibbs, Higgins.

Supervision: Shankaran, Bell, Goldberg, Das, Hensman, Sokol, Poindexter, Faix, Frantz, Truog, Wyckoff, Carlton, Cotten, Higgins. Conflict of Interest: All authors have completed and submitted the ICMJE Form for Disclosure of Potential Conflicts of Interest.

Disclaimer: The comments and views of the authors do not necessarily represent the views of the NICHD.

Additional Contributions: We are indebted to our medical and nursing colleagues and the infants and their parents who agreed to take part in this study. 
Perinatal Institute, Cincinnati Children's Hospital Medical Center, Cincinnati, Ohio

Namasivayam Ambalavanan, MD,

Division of Neonatology, University of Alabama at Birmingham

Claudia Pedroza, PhD,

Department of Pediatrics, McGovern Medical School at the University of Texas Health Science Center at Houston

Athina Pappas, MD,

Department of Pediatrics, Wayne State University, Detroit, Michigan

Abhik Das, PhD,

Social, Statistical, and Environmental Sciences Unit, RTI International, Rockville, Maryland

Aasma S. Chaudhary, BS, RRT,

Department of Pediatrics, University of Pennsylvania, Philadelphia

Richard A. Ehrenkranz, MD,

Department of Pediatrics, Yale University School of Medicine, New Haven, Connecticut

Angelita M. Hensman, MS, RNC-NIC,

Department of Pediatrics, Women \& Infants Hospital, Brown University, Providence, Rhode Island

Krisa P. Van Meurs, MD,

Department of Pediatrics, Division of Neonatal and Developmental Medicine, Stanford University

School of Medicine, Palo Alto, California

Lucile Packard Children's Hospital, Palo Alto, California

Lina F. Chalak, MD, MSCS,

Department of Pediatrics, University of Texas Southwestern Medical Center, Dallas

Shannon E. G. Hamrick, MD,

Emory University School of Medicine, Department of Pediatrics, Children's Healthcare of Atlanta, Atlanta, Georgia

Gregory M. Sokol, MD,

Department of Pediatrics, Indiana University School of Medicine, Indianapolis

Michele C. Walsh, MD, MS,

Department of Pediatrics, Rainbow Babies \& Children's Hospital, Case Western Reserve

University, Cleveland, Ohio

Brenda B. Poindexter, MD, MS,

Perinatal Institute, Cincinnati Children's Hospital Medical Center, Cincinnati, Ohio

Department of Pediatrics, Indiana University School of Medicine, Indianapolis

Roger G. Faix, MD,

Department of Pediatrics, Division of Neonatology, University of Utah School of Medicine, Salt

Lake City

Kristi L. Watterberg, MD, 
University of New Mexico Health Sciences Center, Albuquerque

Ivan D. Frantz III, MD,

Division of Newborn Medicine, Department of Pediatrics, Floating Hospital for Children, Tufts

Medical Center, Boston, Massachusetts

Ronnie Guillet, MD, PhD,

University of Rochester School of Medicine and Dentistry, Rochester, New York

Uday Devaskar, MD,

Department of Pediatrics, University of California, Los Angeles

William E. Truog, MD,

Department of Pediatrics, Children's Mercy Hospital, Kansas City, Missouri

University of Missouri Kansas City School of Medicine, Kansas City

Valerie Y. Chock, MD, MS-Epi,

Department of Pediatrics, Division of Neonatal and Developmental Medicine, Stanford University

School of Medicine, Palo Alto, California

Lucile Packard Children's Hospital, Palo Alto, California

Myra H. Wyckoff, MD,

Department of Pediatrics, University of Texas Southwestern Medical Center, Dallas

Elisabeth C. McGowan, MD,

Department of Pediatrics, Women \& Infants Hospital, Brown University, Providence, Rhode Island

David P. Carlton, MD,

Emory University School of Medicine, Department of Pediatrics, Children's Healthcare of Atlanta, Atlanta, Georgia

Heidi M. Harmon, MD, MS,

Department of Pediatrics, Indiana University School of Medicine, Indianapolis

Jane E. Brumbaugh, MD,

Department of Pediatrics, University of lowa, lowa City

C. Michael Cotten, MD, MHS,

Department of Pediatrics, Duke University, Durham, North Carolina

Pablo J. Sánchez, MD,

Department of Pediatrics, Nationwide Children's Hospital, Columbus, Ohio

Anna Maria Hibbs, MD, and

Department of Pediatrics, Rainbow Babies \& Children's Hospital, Case Western Reserve

University, Cleveland, Ohio

\section{Rosemary D. Higgins, MD}

Eunice Kennedy Shriver National Institute of Child Health and Human Development, National Institutes of Health, Bethesda, Maryland

for the Eunice Kennedy Shriver National Institute of Child Health and Human Development Neonatal Research Network 


\section{Abstract}

IMPORTANCE-Hypothermia initiated at less than 6 hours after birth reduces death or disability for infants with hypoxic-ischemic encephalopathy at 36 weeks' or later gestation. To our knowledge, hypothermia trials have not been performed in infants presenting after 6 hours.

OBJECTIVE-To estimate the probability that hypothermia initiated at 6 to 24 hours after birth reduces the risk of death or disability at 18 months among infants with hypoxic-ischemic encephalopathy.

DESIGN, SETTING, AND PARTICIPANTS-A randomized clinical trial was conducted between April 2008 and June 2016 among infants at 36 weeks' or later gestation with moderate or severe hypoxic-ischemic encephalopathy enrolled at 6 to 24 hours after birth. Twenty-one US Neonatal Research Network centers participated. Bayesian analyses were prespecified given the anticipated limited sample size.

INTERVENTIONS-Targeted esophageal temperature was used in 168 infants. Eighty-three hypothermic infants were maintained at $33.5^{\circ} \mathrm{C}$ (acceptable range, $33^{\circ} \mathrm{C}-34^{\circ} \mathrm{C}$ ) for 96 hours and then rewarmed. Eighty-five noncooled infants were maintained at $37.0^{\circ} \mathrm{C}$ (acceptable range, $\left.36.5^{\circ} \mathrm{C}-37.3^{\circ} \mathrm{C}\right)$.

MAIN OUTCOMES AND MEASURES-The composite of death or disability (moderate or severe) at 18 to 22 months adjusted for level of encephalopathy and age at randomization.

RESULTS-Hypothermic and noncooled infants were term (mean [SD], 39 [2] and 39 [1] weeks' gestation, respectively), and 47 of 83 (57\%) and 55 of $85(65 \%)$ were male, respectively. Both groups were acidemic at birth, predominantly transferred to the treating center with moderate encephalopathy, and were randomized at a mean (SD) of 16 (5) and 15 (5) hours for hypothermic and noncooled groups, respectively. The primary outcome occurred in 19 of 78 hypothermic infants (24.4\%) and 22 of 79 noncooled infants (27.9\%) (absolute difference, 3.5\%; 95\% CI, $-1 \%$ to $17 \%$ ). Bayesian analysis using a neutral prior indicated a $76 \%$ posterior probability of reduced death or disability with hypothermia relative to the noncooled group (adjusted posterior risk ratio, $0.86 ; 95 \%$ credible interval, $0.58-1.29$ ). The probability that death or disability in cooled infants was at least $1 \%, 2 \%$, or $3 \%$ less than noncooled infants was $71 \%, 64 \%$, and $56 \%$, respectively.

CONCLUSIONS AND RELEVANCE-Among term infants with hypoxic-ischemic encephalopathy, hypothermia initiated at 6 to 24 hours after birth compared with noncooling resulted in a $76 \%$ probability of any reduction in death or disability, and a $64 \%$ probability of at least $2 \%$ less death or disability at 18 to 22 months. Hypothermia initiated at 6 to 24 hours after birth may have benefit but there is uncertainty in its effectiveness.

TRIAL REGISTRATION—clinicaltrials.gov Identifier: NCT00614744

Hypoxic-ischemic encephalopathy represents a subset of neonatal encephalopathy, occurring in approximately 1.5 per 1000 live births. ${ }^{1}$ It is an important etiology of neonatal mortality and serious or devastating lifelong cerebral palsy, neurosensory deficits, and cognitive impairments. ${ }^{2}$ Therapeutic hypothermia initiated within 6 hours after birth for moderate or severe hypoxic-ischemic encephalopathy reduced the composite outcome of death or disability at 18 months in multiple randomized clinical trials ${ }^{3-8}$ and improved outcomes at 6 
to 7 years. ${ }^{9,10}$ The American Academy of Pediatrics published a framework to ensure appropriate use of hypothermia. ${ }^{11}$

In all previous neonatal trials, hypothermia was initiated within 6 hours after birth, ${ }^{3-8}$ reflecting a 6-hour therapeutic window for hypothermia after brain ischemia in fetal sheep. ${ }^{12-14}$ However, only 5 fetal sheep were cooled at 8.5 hours after ischemia, ${ }^{14}$ and the results could not exclude the possibility of a longer therapeutic window. Initiating hypothermia before 6 hours after birth can be difficult if infants are born in remote communities and need to be transferred, or if encephalopathy evolves or is recognized after 6 hours. Initiation of hypothermia beyond 6 hours is currently without evidence of benefit. ${ }^{15}$ A definitive trial to determine benefit or harm cannot be conducted for this uncommon condition because even large research networks have an insufficient number of patients to achieve high statistical power in a reasonable time. To provide the most feasible estimate of treatment effect, a multicenter, randomized clinical trial was conducted over 8 years among infants with moderate or severe hypoxic-ischemic encephalopathy treated with hypothermia initiated at or after 6 hours but before 24 hours of age compared with noncooled infants. Bayesian analyses were performed to estimate the probability that hypothermia reduced the risk of death or disability at 18 months.

\section{Methods}

\section{Participants}

Trial enrollment occurred between April 2008 and July 2014 and follow-up was completed in June 2016 at 21 centers of the Eunice Kennedy Shriver National Institutes of Child Health and Human Development Neonatal Research Network located across the United States. The full trial protocol is available in Supplement 1. Each center received institutional review board approval and infants were enrolled after written informed parental consent was obtained. Newborns with gestational age 36 weeks or later and postnatal age 6 to 24 hours were screened for eligibility if they were admitted to a participating neonatal intensive care unit with a diagnosis of encephalopathy, perinatal asphyxia, or neurological depression. Enrollment until 24 hours of age was based on the variability in the manifestations of newborn encephalopathy, ${ }^{16}$ ongoing injurious processes in the hours to days after hypoxiaischemia, ${ }^{17}$ benefit from hypothermia initiated at 12 hours after ischemia in a preclinical study, ${ }^{18}$ and the uncertainty in extrapolating from animal to human newborns.

Inclusion criteria were identical to the prior Neonatal Research Network hypothermia trial ${ }^{4}$ except for postnatal age. Infants who fulfilled biochemical or clinical criteria and were determined to have seizures or moderate or severe encephalopathy on examination by certified examiners were eligible. ${ }^{4}$ Infants without moderate or severe encephalopathy by examination but with clinical seizures were classified as having moderate encephalopathy. Exclusion criteria included a core temperature of less than $34^{\circ} \mathrm{C}$ for more than 1 hour, known anomaly, chromosomal aberration, birth weight less than $1800 \mathrm{~g}$, in extremis condition, and parental or attending physician refusal. Race/ethnicity was obtained by maternal report using fixed categories to ensure group comparability along with other demographic variables. 


\section{Randomization}

Infants were stratified by postnatal age ( $₫ 2$ hours or $>12$ hours) and stage of encephalopathy (moderate or severe), and they were randomly assigned by telephone by the data center to hypothermia or noncooling using a computer-generated permutated block algorithm with block size of 2 and 4 with a 1:1 ratio.

\section{Intervention}

Before randomization, temperature control was per center practices. The hypothermia group underwent whole-body cooling similar to the Neonatal Research Network hypothermia trial ${ }^{4,19}$ to maintain esophageal temperature at $33.5^{\circ} \mathrm{C}$ (acceptable range, $33.0^{\circ} \mathrm{C}-34.0^{\circ} \mathrm{C}$ ) using a Hyper-Hypothermia Blanketrol system (Cincinnati Sub-Zero). The duration of hypothermia was lengthened from 72 hours $^{4}$ to 96 hours based on preclinical data before 2008 that a longer duration of hypothermia was needed to achieve neuroprotection with increasing delays between hypoxia-ischemia and initiation of cooling. ${ }^{18,20}$ At 96 hours, rewarming was conducted at $0.5^{\circ} \mathrm{C}$ per hour using the Blanketrol system and completed using a radiant warmer to maintain esophageal temperature of $37.0^{\circ} \mathrm{C}$ over 5 hours. Temperatures were recorded every 15 minutes during the first 3 hours of cooling, every hour until 12 hours, and at 4-hour intervals through the remainder of cooling and rewarming. The noncooled group was treated with an esophageal temperature probe and temperatures maintained at $37.0^{\circ} \mathrm{C}$ (acceptable range, $36.5^{\circ} \mathrm{C}-37.3^{\circ} \mathrm{C}$ ). Infants were cared for on radiant warmers and the control set point for the skin temperature was adjusted to achieve the desired esophageal temperature. An algorithm was used to correct hyperthermia by ensuring appropriate thermal care if the esophageal temperature exceeded $37.3^{\circ} \mathrm{C}$, and a tepid bath and/or cooling blanket if the temperature exceeded $37.5^{\circ} \mathrm{C}$. Temperatures were recorded every 4 hours in the noncooled group. At 108 hours, esophageal temperature probes of both groups were removed and temperature control was resumed per local practice.

\section{Outcomes}

The primary outcome was death or disability, either moderate or severe, at 18 to 22 months of age. Certified examiners trained to reliability ${ }^{21}$ and masked to treatment assignment conducted a neurological examination and psychometric testing, assessed growth, and reviewed vision and hearing with the family. The Bayley Scales of Infant Development III were used to obtain cognitive, language, and motor scores (reported mean [SD] score, 100 [15]; range, 55-145). ${ }^{22}$ The Gross Motor Function Classification Score (GMFCS; range, 0 [normal] to 5 [worst]) was used to classify motor findings. ${ }^{23}$ Severe disability was defined as any of the following: a cognitive score less than 70, a GMFCS level of 3 to 5, and blindness or hearing impairment with inability to follow commands despite amplification. Moderate disability was defined as a cognitive score between 70 and 84 and any of the following: a GMFCS level of 2, an active seizure disorder (antiepileptic drugs in use), or a hearing deficit with the ability to follow commands after amplification. ${ }^{4}$ Infants who did not meet the primary outcome were categorized as either mild disability or normal. Mild disability was defined by a cognitive score of 70 to 84 alone or a cognitive score of 85 or greater, and any of the following: a GMFCS level of 1 or 2 , a seizure disorder (without medication), or a hearing deficit with the ability to follow commands without amplification. 
Prespecified secondary outcomes were the frequency of death alone, moderate-severe disability alone, disability (severe, moderate, and mild), disability based on level of encephalopathy, seizures (with or without electroencephalograms), do not resuscitate order (DNR), DNR and support withdrawn, DNR and survival or death, and nonbrain organ dysfunction. The latter 2 are not reported. Outcomes not pre-specified were adverse events, in-hospital organ system morbidities, components of disability, normal infants (cognitive score of $\geq 85$, a normal GMFCS level, no neurosensory deficits, and no seizures), and growth parameters at follow-up.

\section{Sample Size and Statistical Analyses}

The effect size was expected to be smaller than the prior Neonatal Research Network hypothermia trial (risk ratio [RR], 0.72; 95\% CI, 0.54-0.95). ${ }^{4}$ A sample size of 168 was predefined and represented the largest sample that could be attained in a feasible time interval (6-year enrollment). A Bayesian analysis was prespecified to estimate the probability of treatment benefit based on recommendations for trials of rare conditions with limited sample size and power in frequentist analyses to identify conclusive treatment effects. $^{24}$

In Bayesian analyses, the probability of treatment effect (posterior probability) is estimated after the trial and incorporates the prior probability estimated from the best data from previous studies (clinical trials or pilot trials). ${ }^{25}$ Judgment of the prior probability may vary and be neutral, enthusiastic, or skeptical. Therefore, analyses were performed using 3 different prior probabilities: (1) a neutral prior, assuming no treatment effect (RR, 1.0); (2) an enthusiastic prior, assuming a $28 \%$ reduction in the risk of death or disability as in the earlier Neonatal Research Network trial ${ }^{4}$ (RR, 0.72); and (3) a skeptical prior, assuming a $10 \%$ increase in the risk of death or disability (RR, 1.10). Whether neutral, enthusiastic, or skeptical, assessments of prior probability involve uncertainty about the minimum and maximum likely treatment effects. To reflect this uncertainty in each analysis, a probability distribution for the treatment effect with the $95 \%$ credible intervals that ranged from half to twice the assumed RR (SD, 0.35 in the log scale) was used. For example, the probability distribution for the neutral prior was centered at an RR of 1.0 (mean of 0 in the log scale) with a $50 \%$ prior probability of a better outcome, a $50 \%$ prior probability of a worse outcome, and a 95\% credible interval for the RR of 0.5 to 2.0 (eAppendix in Supplement 2). The RR of 0.5 to 2.0 includes treatment effects for major clinical outcomes of the size observed in almost all large clinical trials. ${ }^{26}$ For adequately powered trials, differences between neutral, enthusiastic, and skeptical priors have almost no effect on the posterior probability. However, for smaller trials, Bayesian analyses allow assessment of how much the estimated probability of a treatment effect is affected by differing assessments of the prior evidence.

All analyses followed the intention-to-treat principle. A binomial model was used with a log link to estimate the posterior RR for different binary outcomes for the hypothermia group compared with the noncooled group. The model to obtain the adjusted RR (aRR) included 3 main effects: treatment (hypothermia or noncooling), age at time of randomization ( $₫ 2$ hours or $>12$ hours), and level of encephalopathy (moderate or severe). Center was not 
included because models did not converge with center as a covariate. The original analysis plan specified a logistic model. This represented an oversight as the intent was to present adjusted relative risks to quantify the treatment effect. The decision to use a log binomial model was made prior to the derivation of the primary outcome and all analyses.

Interactions of treatment with age at enrollment, level of encephalopathy at randomization, and sex on the primary outcome were assessed with a log-linear model. Bayesian analyses were used to determine probabilities for the absolute risk difference (binomial model) and adjusted cognitive scores (linear regression). $P$ values from parallel frequentist analyses are provided for outcomes not pre-specified, using 2-sided $\chi^{2}$, Fisher exact, Wilcoxon, and $t$ tests; 1 -sided $t$ tests were used for absolute differences. A $P<.05$ was considered significant and was not adjusted for multiple comparisons. Statistical software for Bayesian analysis was JAGS version 4.6 and OpenBUGS version 3.2.3., and for frequentist analysis was SAS version 9.3 (SAS Institute). The data safety monitoring committee reviewed safety after every 20 infants and effectiveness at 33\%, 50\%, and $75 \%$ of outcome accrual.

\section{Results}

There were 168 participants and 83 were randomly assigned to hypothermia and 85 to noncooling (Figure 1). Hypothermic and noncooled infants were term (mean [SD], 39 [2] and 39 [1] weeks' gestation, respectively), and 47 of 83 (57\%) and 55 of 85 (65\%) were male, respectively. Emergency cesarean delivery was performed for 99 of 168 infants (59\%), of whom $146(87 \%)$ were transferred to the treating center (Table 1). At birth, intubation was performed in 92 of 168 infants (55\%) and chest compressions were performed in 44 of 168 infants (26\%). Hypothermic and noncooled infants were randomized at a mean (SD) of 16 (5) and 15 (5) hours, respectively. Enrollment beyond 12 hours after birth occurred in 114 of 168 infants (68\%) and moderate encephalopathy was found in 151 of 168 infants (90\%). Ten infants in each group were enrolled based on clinical seizures without moderate or severe encephalopathy. Infants with incomplete or no follow-up $(n=11)$ were similar to those with a known outcome (eTable 1 in Supplement 2).

Following hypothermia induction, mean (SD) esophageal temperature was maintained at $33.3(0.3)^{\circ} \mathrm{C}$ between 3 and 96 hours (eFigure in Supplement 2). The mean (SD) esophageal temperature for the noncooled group during the intervention was $36.8(0.5)^{\circ} \mathrm{C}$. In the noncooled group, the median number of esophageal temperatures per infant below $36.5^{\circ} \mathrm{C}$ was 1 (interquartile range [IQR], $0-3$ ) and the mean of these values was $36.2^{\circ} \mathrm{C}$ (IQR, $\left.35.9^{\circ} \mathrm{C}-36.4^{\circ} \mathrm{C}\right)$. The median number of esophageal temperatures per infant greater than $37.3^{\circ} \mathrm{C}$ was 1 (IQR, $0-4$ ) and the mean of these values was $37.5^{\circ} \mathrm{C}\left(\mathrm{IQR}, 37.4^{\circ} \mathrm{C}-37.7^{\circ} \mathrm{C}\right.$ ). Interventions to reduce elevated temperature were performed in 27 of 85 infants (32\%) in the noncooled group; 24 infants (28\%) received a tepid bath and 7 infants (8\%) were treated with a cooling blanket.

During the intervention and rewarming, unmasked observers recorded 13 and 6 adverse events in the hypothermia and noncooled groups, respectively (Table 2). One infant (hypothermia) developed subcutaneous fat necrosis and 1 infant (noncooled) developed diabetes insipidus, both remote from the intervention. There were no group differences in 
organ system morbidities or need for extracorporeal membrane oxygenation. A blood glucose concentration greater than $150 \mathrm{mg} / \mathrm{dL}$ occurred more frequently in the hypothermia than the noncooled group (to convert glucose to millimoles per liter, multiply by 0.0555 ).

Complete follow-up at a mean (SD) of 21 (3) months was achieved among 69 of 74 (93\%) and 72 of 78 (92\%) hypothermia and noncooled survivors to discharge, respectively. There were 9 deaths in each group. There were minimal missing data for the components of disability among survivors, which did not prevent assignment of a primary outcome except for 2 infants with incomplete follow-up evaluations (Figure 1). Death or disability (moderate or severe) at follow-up was known for 157 infants (93.5\%) and occurred in 19 of 78 (24.4\%) of the hypothermia group and 22 of 79 (27.9\%) of the noncooled group (absolute difference, $3.5 \%$; $95 \% \mathrm{CI},-1 \%$ to $17 \%$; Table 3 ). Bayesian analysis using a neutral prior indicated a $76 \%$ posterior probability of reduced death or disability with a posterior aRR of $0.86(95 \%$ credible interval, 0.58-1.29) (Figure 2). The corresponding frequentist aRR was 0.81 (95\% CI, 0.44-1.51). Further, 73\% and 68\% probabilities were identified for reduction in death and in moderate-severe disability, respectively, under the neutral prior. Expressed as an absolute risk difference, the posterior probability that death or disability for hypothermia using a neutral prior was at least $1 \%, 2 \%$, or $3 \%$ less compared with noncooled treatment was $71 \%, 64 \%$, and $56 \%$, respectively. A $2 \%$ absolute risk difference was associated with a 3.2-times (64\%/20\%) higher probability of reduced compared with increased death or disability among hypothermia relative to noncooled infants, assuming a range of risk differences viewed as equivalent (Figure 2). Using an enthusiastic prior, the posterior probability that death or disability was at least $1 \%, 2 \%$, or $3 \%$ less compared with noncooled increased to $86 \%, 80 \%$, and $74 \%$, respectively. Death or moderate-severe disability did not differ by age at randomization: 6 of 25 infants (24.0\%) and 7 of 26 infants (26.9\%) when randomized at 12 hours or less, and 13 of 53 infants (24.5\%) and 15 of 53 infants (28.3\%) when randomized between 12 and 24 hours in the hypothermia and noncooled groups, respectively. There were no interactions between treatment and age at randomization, level of encephalopathy, or sex for the primary outcome (Bayesian probability of an interaction, $46 \%, 38 \%$, and $22 \%$, respectively).

Other prespecified and exploratory outcomes did not differ between groups (eTable 2 in Supplement 2). Although Bayley cognitive scores did not differ, they contributed to the extent of disability within each group; a post-hoc Bayesian analysis (neutral prior) indicated a $97 \%$ probability of higher scores among hypothermia infants. A post-hoc aRR for survival of infants with a normal outcome was 0.98 (95\% credible intervals, 0.76-1.26; neutral prior).

\section{Discussion}

Among term infants with hypoxic-ischemic encephalopathy, hypothermia initiated at 6 to 24 hours after birth resulted in a $76 \%$ probability of any reduction in death or disability using a Bayesian analysis with a neutral prior. The probability that death or disability was at least $2 \%$ less in hypothermia compared with noncooled infants was $64 \%$. Enrolled infants met criteria for hypothermia of the earlier Neonatal Research Network trial. ${ }^{4}$ Death or disability 
(moderate or severe) was known for $93.5 \%$ of enrollees and follow-up assessments were performed by examiners blinded to the intervention.

It can be difficult to study therapies for rare diseases or uncommon features of previously studied disease processes. Extrapolation from animal studies has limitations. ${ }^{27}$ The therapeutic window during which hypothermia may modify hypoxic-ischemic brain injury may differ between preclinical studies and human newborns owing to species maturation, methods to induce hypoxia-ischemia, and outcomes studied. Randomized clinical trials are unlikely to have sufficient power to identify clinically important treatment effects in traditional frequentist analysis. This is especially pertinent to a trial of hypothermia initiated after 6 hours of age as it addresses a small subset of infants with moderate-severe encephalopathy. Furthermore, based on preclinical studies, ${ }^{12-14}$ hypothermia started after 6 hours was anticipated to provide less neuroprotection than hypothermia started before 6 hours, making it even less feasible to achieve high power even in the Neonatal Research Network, with 21 centers serving large delivery cohorts and referral bases throughout the United States. However, the high rates of potentially catastrophic outcomes associated with hypoxic-ischemic encephalopathy, and reports of initiating hypothermia after 6 hours in a subset of infants with moderate-severe encephalopathy without any systematic study, provided justification to undertake this trial.

With the sample size studied, traditional frequentist analysis identified no significant difference for death or disability between the hypothermic and noncooled groups. A frequentist analysis of an underpowered trial would provide little help for clinicians treating infants with encephalopathy who present beyond 6 hours. However, frequentist analyses do not allow calculation of the probability of a specified benefit while Bayesian methods allow for direct assessment of the probability of treatment effect based on the trial results. ${ }^{24,25,28} \mathrm{~A}$ series of absolute risk differences in death or disability were provided to assess effect size. An absolute risk reduction of $1 \%$ or $2 \%$ in death or moderate-severe disability may be viewed as clinically important given the seriousness of the outcome. Perinatal and adult therapies have been recommended at a similar low absolute risk reduction for major adverse outcomes. A risk reduction of $1.6 \%$ for cerebral palsy has been reported among preterm newborns whose mothers were treated with magnesium sulfate, ${ }^{29}$ a treatment now widely used in obstetrics. ${ }^{30}$ Statins have been recommended in adults with a cardiovascular disease risk of $10 \%$ but without cardiovascular disease ${ }^{31}$ based on absolute risk reductions of $0.4 \%$ and $1.4 \%$ for all-cause and composite cardiovascular mortality, respectively. ${ }^{32}$

The reduction in death or disability for hypothermic compared with noncooled infants is suggestive but not conclusive. No evidence of commensurate harm was found. Adverse events, prespecified and those not prespecified, occurred in more hypothermic than noncooled infants but did not differ by frequentist analysis. The number of deaths per group was the same, but the Bayesian analysis indicated the aRR favored hypothermia and the posterior probability of reduced death was $73 \%$ under a neutral prior. A decision to use hypothermia at 6 to 24 hours will need to consider the probability of benefit, the frequency of adverse events, and the availability of evidence-based alternative treatments. 
In all neonatal trials, hypothermia initiated at less than 6 hours reduced death or disability, ${ }^{33}$ and therefore a prior based on an RR between 1.0 (no benefit) and 0.72 (the benefit identified in the previous Neonatal Research Network hypothermia trial ${ }^{4}$ ) might be considered appropriate. If so, the estimated probabilities for any reduction or a greater than $1 \%$ or greater than $2 \%$ absolute reduction in death or disability would be somewhat higher and intermediate between the estimates using a neutral prior and those using an enthusiastic prior. Given these considerations, estimated probabilities based on a neutral prior could be considered conservative. Since the initiation of this trial, there is little new information on late hypothermia treatment to provide an estimate of treatment effect. A trial from China randomized 93 newborns within 10 hours of birth to hypothermia or normothermia; only 9 infants received hypothermia between 6 and 10 hours. ${ }^{34}$ Single-center and registry data reported initiation of hypothermia after 6 hours but did not provide treatment effect. ${ }^{15,35}$

Hypoxic-ischemic encephalopathy resulting in moderate or severe disability is a devastating outcome. The results of this trial should not change the priority of early identification of infants with hypoxic-ischemic encephalopathy and initiation of hypothermia at less than 6 hours. This trial provides an approach to estimate the treatment effect for uncommon diseases in the largest feasible clinical trial and avoid the biases inherent in observational studies.

\section{Limitations}

This study has several limitations. During this trial, the Neonatal Research Network initiated the Optimizing Cooling trial to study longer $\left(120\right.$ hours) or deeper $\left(32^{\circ} \mathrm{C}\right)$ cooling initiated at less than 6 hours of age. ${ }^{36,37}$ The Optimizing Cooling trial was stopped early partly owing to safety concerns for increased in-hospital mortality among infants cooled for 120 rather than 72 hours. Whether the current trial results would differ if the intervention was shortened to 72 hours cannot be answered. Elevated esophageal temperature occurred among noncooled infants and such temperatures have been associated with a greater risk of death or disability in prior trials. ${ }^{38-40}$ The algorithm used in noncooled infants largely mitigated the extent and duration of esophageal temperatures greater than $37.3^{\circ} \mathrm{C}$ compared with the earlier Neonatal Research Network hypothermia trial. ${ }^{4}$ Also, the reason for presentation at or beyond 6 hours was not always known.

\section{Conclusions}

Among term infants with hypoxic-ischemic encephalopathy, hypothermia initiated at 6 to 24 hours after birth compared with noncooling resulted in a $76 \%$ probability of any reduction in death or disability, and a $64 \%$ probability of at least $2 \%$ less death or disability at 18 to 22 months. Hypothermia initiated at 6 to 24 hours after birth may have benefit but there is uncertainty in its effectiveness.

\section{Supplementary Material}

Refer to Web version on PubMed Central for supplementary material. 


\section{Acknowledgments}

Disclosures: Drs Laptook, Pedroza, Walsh, Faix, and Frantz reported receiving grants from the Eunice Kennedy Shriver National Institute of Child Health and Human Development (NICHD). Drs Das and Ehrenkranz reported receiving grants from the NICHD and the National Institutes of Health. Dr Sokol reports receiving grants from the National Institutes of Health. Dr Brumbaugh reported that the University of Iowa received grant funding from the NICHD as a member of the Neonatal Research Network. Drs Cotten and Sánchez reported receiving grants from the NICHD Neonatal Research Network. No other disclosures were reported.

Funding/Support: The National Institutes of Health, the NICHD, the National Center for Research Resources, and the National Center for Advancing Translational Sciences provided grant support for the Neonatal Research Network through cooperative agreements.

Role of the Funder/Sponsor: NICHD staff participated in the design and conduct of the study; collection, management, analysis, and interpretation of the data; preparation, review and approval of the manuscript; and the decision to submit the manuscript for publication. The National Center for Research Resources and the National Center for Advancing Translational Sciences provided funding for infrastructure support for the Neonatal Research Network but did not participate in the design and conduct of the study; collection, management, analysis, and interpretation of the data; preparation, review and approval of the manuscript; and the decision to submit the manuscript for publication.

\section{Group Information}

The following investigators, in addition to those listed as authors, participated in this study: NRN Steering Committee Chairs: Alan H. Jobe, MD, PhD, University of Cincinnati (20032006); Michael S. Caplan, MD, University of Chicago, Pritzker School of Medicine (20062011); and Richard A. Polin, MD, Division of Neonatology, College of Physicians and Surgeons, Columbia University, (2011-present). Alpert Medical School of Brown University and Women \& Infants Hospital of Rhode Island: Martin Keszler, MD; William Oh, MD; Betty R. Vohr, MD; Barbara Alksninis, RNC, PNP; Kristin Basso, MaT, RN; Joseph Bliss, MD, PhD; Carmena Bishop; Robert T. Burke, MD, MPH; William Cashore, MD; Melinda Caskey, MD; Dan Gingras, RRT; Nicholas Guerina, MD, PhD; Hussnain Mirza, MD; Katharine Johnson, MD; Mary Lenore Keszler, MD; Andrea M. Knoll; Theresa M. Leach, MEd, CAES; Martha R. Leonard, BA, BS; Emilee Little, RN, BSN; Ross Sommers, MD; Birju A. Shah, MD, MPH; Bonnie E. Stephens, MD; Suzy Ventura; Elisa Vieira, RN, BSN; and Victoria E. Watson, MS, CAS. Case Western Reserve University, Rainbow Babies \& Children's Hospital: Deanne E. Wilson-Costello, MD; Nancy S. Newman, RN; Beau Batton, MD; Monika Bhola, MD; Juliann M. Di Fiore, BSEE; Harriet G. Friedman, MA; Bonnie S. Siner, RN; Eileen K. Stork, MD; Gulgun Yalcinkaya, MD; and Arlene Zadell, RN. Children's Mercy Hospital, University of Missouri Kansas City School of Medicine: Eugenia K. Pallotto, MD, MSCE; Howard W. Kilbride, MD; Cheri Gauldin, RN, BS, CCRC; Anne Holmes, RN, MSN, MBA-HCM, CCRC; Kathy Johnson, RN, CRC; and Allison Knutson, BSN, RNC-NIC. Cincinnati Children's Hospital Medical Center, University of Cincinnati Medical Center, and Good Samaritan Hospital: Kurt Schibler, MD; Suhas G. Kallapur, MD; Kimberly Yolton, PhD; Cathy Grisby, BSN, CCRC; Barbara Alexander, RN; Estelle E. Fischer, MHSA, MBA; Teresa L. Gratton, PA; Jody Hessling, MSN, RN; Lenora Jackson, CRC; Kristin Kirker, CRC; Stephanie Merhar, MD, MS; Holly L. Mincey, MS, RN, BSN; Greg Muthig, BA; and Sandra Wuertz, RN, BSN, CLC. Duke University School of Medicine, University Hospital, University of North Carolina, and Duke Regional Hospital: Kimberley A. Fisher, PhD, FNP-BC, IBCLC; Sandra Grimes, RN, BSN; Joanne Finkle, RN, JD; Ricki F. Goldstein, MD; Kathryn E. Gustafson, PhD; William F. 
Malcolm, MD; Patricia L. Ashley, MD, PhD; Kathy J. Auten, MSHS; Melody B. Lohmeyer, RN, MSN; Matthew M. Laughon, MD, MPH; Carl L. Bose, MD; Janice Bernhardt, MS, RN; Cindy Clark, RN; Diane D. Warner, MD, MPH; Janice Wereszcsak, CPNP; and Sofia Aliaga, MD, MPH. Emory University, Children's Healthcare of Atlanta, Grady Memorial Hospital, and Emory University Hospital Midtown: Barbara J. Stoll, MD; Ellen C. Hale, RN, BS, CCRC; Yvonne Loggins, RN; Diane I. Bottcher, MSN, RN; Colleen Mackie, BS, RT; Maureen Mulligan LaRossa, RN; Ira Adams-Chapman, MD; Lynn C. Wineski, RN, MS; and Sheena L. Carter, PhD. Eunice Kennedy Shriver National Institute of Child Health and Human Development: Stephanie Wilson Archer, MA. Indiana University, University Hospital, Methodist Hospital, Riley Hospital for Children at Indiana University Health, and Eskenazi Health: Lu-Ann Papile, MD; Jessica Bissey, PsyD, HSPP; Lon G. Bohnke, MS; Ann B. Cook, MS; Anna M. Dusick, MD (deceased); Susan Gunn, NNP-BC, CCRC; Dianne E. Herron, RN, CCRC; Abbey C. Hines, PsyD; Darlene Kardatzke, MD (deceased); Carolyn Lytle, MD, MPH; Heike M. Minnich, PsyD, HSPP; Leslie Richard, RN; Lucy C. Smiley, CCRC; and Leslie Dawn Wilson, BSN CCRC. McGovern Medical School at the University of Texas Health Science Center at Houston, Children's Memorial Hermann Hospital: Kathleen A. Kennedy, MD, MPH; Julie Arldt-McAlister, MSN, APRN; Katrina Burson, RN, BSN; Allison G. Dempsey, PhD; Andrea F. Duncan, MD, MSClinRes; Patricia W. Evans, MD; Carmen Garcia, RN, BSN; Margarita Jimenez, MD, MPH; Janice John, CPNP; Patrick M. Jones, MD, MA; M. Layne Lillie, RN, BSN; Karen Martin, RN; Sara C. Martin, RN, BSN; Georgia E. McDavid, RN; Patti L. Pierce Tate, RCP; Shawna Rodgers, RN, BSN; Saba Khan Siddiki, MD; Daniel K. Sperry, RN; and Sharon L. Wright, MT (ASCP). Nationwide Children's Hospital and the Ohio State University Wexner Medical Center: Leif D. Nelin, MD; Sudarshan R. Jadcherla, MD; Patricia Luzader, RN; and Christine A. Fortney, $\mathrm{PhD}$, RN. RTI International: Dennis Wallace, PhD; Marie G. Gantz, PhD; Kristin M. Zaterka-Baxter, RN, BSN, CCRP; Margaret M. Crawford, BS, CCRP; Jenna Gabrio, BS, CCRP; Scott A. McDonald, BS; Jamie E. Newman, PhD, MPH; Jeanette O'Donnell Auman, BS; Carolyn M. Petrie Huitema, MS, CCRP; and James W. Pickett II, BS. Stanford University and Lucile Packard Children's Hospital: David K. Stevenson, MD; Susan R. Hintz, MD, MS-Epi; M. Bethany Ball, BS, CCRC; Elizabeth F. Bruno, PhD; Maria Elena DeAnda, PhD; Anne M. DeBattista, RN, PNP, PhD; Lynne C. Huffman, MD; Casey E. Krueger, PhD; Melinda S. Proud, RCP; Nicholas H. St. John, PhD; and Hali E. Weiss, MD. Tufts Medical Center, Floating Hospital for Children: Elisabeth C. McGowan, MD; John M. Fiascone, MD; Brenda L. MacKinnon, RNC; Ana Brussa, MS, OTR/L; Anne Furey, MPH; Brian Gilchrist, MD; Juliette C. Madan, MD, MS; Ellen Nylen, RN, BSN; and Cecelia Sibley, PT, MHA. University of Alabama at Birmingham Health System and Children's Hospital of Alabama: Waldemar A. Carlo, MD; Myriam Peralta-Carcelen, MD, MPH; Monica V. Collins, RN, BSN, MaEd; Shirley S. Cosby, RN, BSN; Vivien A. Phillips, RN, BSN; Richard V. Rector, PhD; and Sally Whitley, MA, OTR-L, FAOTA. University of California-Los Angeles, Mattel Children's Hospital, Santa Monica Hospital, Los Robles Hospital and Medical Center, and Olive View Medical Center: Meena Garg, MD; Isabell B. Purdy, PhD, CPNP; Teresa Chanlaw, MPH; and Rachel Geller, RN, BSN. University of Iowa and Mercy Medical Center: Tarah T. Colaizy, MD, MPH; Karen J. Johnson, RN, BSN; Diane L. Eastman, RN, CPNP, MA; Michael J. Acarregui, MD, MBA; Jacky R. Walker, RN; Claire A. Lindauer, RN; Jonathan M. Klein, MD; Nancy J. Krutzfield, RN, MA; Jeffrey L. 
Segar, MD; John M. Dagle, MD, PhD; Julie B. Lindower, MD, MPH; Steven J. McElroy, MD; Glenda K. Rabe, MD, MME; Robert D. Roghair, MD; Lauritz R. Meyer, MD; Dan L. Ellsbury, MD; Donia B. Campbell, RNC-NIC; Cary R. Murphy, MD; and Vipinchandra Bhavsar, MB, BS. University of New Mexico Health Sciences Center: Robin K. Ohls, MD; Conra Backstrom Lacy, RN; Sandra Sundquist Beauman, MSN, RNC; Sandra Brown, BSN; Erika Fernandez, MD; Andrea Freeman Duncan, MD; Janell Fuller, MD; Carol Hartenberger, BSN, MPH; and Jean R. Lowe, PhD. University of Pennsylvania, Hospital of the University of Pennsylvania, Pennsylvania Hospital, and Children's Hospital of Philadelphia: Barbara Schmidt, MD, MSc; Haresh Kirpalani, MB, MSc; Sara B. DeMauro, MD, MSCE; Kevin C. Dysart, MD; Soraya Abbasi, MD; Toni Mancini, RN, BSN, CCRC; Dara M. Cucinotta, RN; Judy C. Bernbaum, MD; Marsha Gerdes, PhD; and Hallam Hurt, MD. University of Rochester Medical Center, Golisano Children's Hospital, and the University of Buffalo Women's and Children's Hospital of Buffalo: Carl D'Angio, MD; Satyan Lakshminrusimha, MD; Nirupama Laroia, MD; Gary J. Myers, MD; Kelley Yost, PhD; Stephanie Guilford, BS; Rosemary L. Jensen; Karen Wynn, NNP, RN; Osman Farooq, MD; Anne Marie Reynolds, MD, MPH; Michael G. Sacilowski, MAT; Holly I. M. Wadkins, MA; Ashley Williams, MS Ed; Joan Merzbach, LMSW; Patrick Conway, MS; and Melissa Bowman, MSN. University of Texas Southwestern Medical Center, Parkland Health \& Hospital System, and Children's Medical Center Dallas: Luc P. Brion, MD; Roy J. Heyne, MD; Lijun Chen, PhD, RN; Diana M. Vasil, MSN, BSN, RNC-NIC; Sally S. Adams, MS, RN, CPNP; Catherine Twell Boatman, MS, CIMI; Alicia Guzman; Elizabeth T. Heyne, MS, MA, PA-C, PsyD; Lizette E. Lee, RN; Melissa H. Leps, RN; Linda A. Madden, BSN, RN, CPNP; Nancy A. Miller, RN; and Emma Ramon, RNC-NIC, RN, BSN. University of Utah Medical Center, Intermountain Medical Center, LDS Hospital, and Primary Children's Medical Center: Bradley A. Yoder, MD; Anna Bodnar, MD; Karen A. Osborne, RN, BSN, CCRC; Cynthia Spencer, RNC; R. Edison Steele, RN; Mike Steffen, PhD; Karena Strong, RN, BSN; Kimberlee Weaver-Lewis, RN, BSN; Shawna Baker, RN; Sarah Winter, MD; Karie Bird, RN, BSN; and Jill Burnett, RNC, BSN. Wayne State University, University of Michigan, Hutzel Women's Hospital, and Children's Hospital of Michigan: Beena G. Sood, MD, MS; Rebecca Bara, RN, BSN; Kirsten Childs, RN, BSN; Lilia C. De Jesus, MD; Bogdan Panaitescu, MD; Sanjay Chawla, MD; Jeannette E. Prentice, MD; Laura A. Goldston, MA; Eunice Hinz Woldt, RN, MSN; Girija Natarajan, MD; Monika Bajaj, MD; John Barks, MD; Mary Christensen, RT; and Stephanie A. Wiggins, MS. Yale-New Haven Children's Hospital: Monica Konstantino, RN, BSN; Matthew Bizzarro, MD; Nancy Close, PhD; JoAnn Poulsen, RN; Elaine Romano, MSN; and Janet Taft, RN, BSN.

\section{References}

1. Neonatal Encephalopathy and Neurologic Outcome. 2nd. Washington, DC: American College of Obstetricians and Gynecologists; 2014. American College of Obstetricians and Gynecologists, American Academy of Pediatrics.

2. Volpe JJ. Neonatal encephalopathy: an inadequate term for hypoxic-ischemic encephalopathy. Ann Neurol. 2012; 72(2):156-166. [PubMed: 22926849]

3. Gluckman PD, Wyatt JS, Azzopardi D, et al. Selective head cooling with mild systemic hypothermia after neonatal encephalopathy: multicentre randomised trial. Lancet. 2005; 365(9460):663-670. [PubMed: 15721471] 
4. Shankaran S, Laptook AR, Ehrenkranz RA, et al. National Institute of Child Health and Human Development Neonatal Research Network. Whole-body hypothermia for neonates with hypoxicischemic encephalopathy. N Engl J Med. 2005; 353(15):1574-1584. [PubMed: 16221780]

5. Azzopardi DV, Strohm B, Edwards AD, et al. TOBY Study Group. Moderate hypothermia to treat perinatal asphyxial encephalopathy. N Engl J Med. 2009; 361(14):1349-1358. [PubMed: 19797281]

6. Zhou WH, Cheng GQ, Shao XM, et al. China Study Group. Selective head cooling with mild systemic hypothermia after neonatal hypoxic-ischemic encephalopathy: a multicenter randomized controlled trial in China. J Pediatr. 2010; 157(3):367-372. 372.e1-372.e3. [PubMed: 20488453]

7. Simbruner G, Mittal RA, Rohlmann F, Muche R, neo.nEURO.network Trial Participants. Systemic hypothermia after neonatal encephalopathy: outcomes of neo.nEURO.network RCT. Pediatrics. 2010; 126(4):e771-e778. [PubMed: 20855387]

8. Jacobs SE, Morley CJ, Inder TE, et al. Infant Cooling Evaluation Collaboration. Whole-body hypothermia for term and near-term newborns with hypoxic-ischemic encephalopathy: a randomized controlled trial. Arch Pediatr Adolesc Med. 2011; 165(8):692-700. [PubMed: 21464374]

9. Shankaran S, Pappas A, McDonald SA, et al. Eunice Kennedy Shriver NI Neonatal Research CHD Network. Childhood outcomes after hypothermia for neonatal encephalopathy. N Engl J Med. 2012; 366(22):2085-2092. [PubMed: 22646631]

10. Azzopardi D, Strohm B, Marlow N, et al. TOBY Study Group. Effects of hypothermia for perinatal asphyxia on childhood outcomes. N Engl J Med. 2014; 371(2):140-149. [PubMed: 25006720]

11. Papile LA, Baley JE, Benitz W, et al. Committee on Fetus and Newborn. Hypothermia and neonatal encephalopathy. Pediatrics. 2014; 133(6):1146-1150. [PubMed: 24864176]

12. Gunn AJ, Gunn TR, de Haan HH, Williams CE, Gluckman PD. Dramatic neuronal rescue with prolonged selective head cooling after ischemia in fetal lambs. J Clin Invest. 1997; 99(2):248-256. [PubMed: 9005993]

13. Gunn AJ, Gunn TR, Gunning MI, Williams CE, Gluckman PD. Neuroprotection with prolonged head cooling started before postischemic seizures in fetal sheep. Pediatrics. 1998; 102(5):10981106. [PubMed: 9794940]

14. Gunn AJ, Bennet L, Gunning MI, Gluckman PD, Gunn TR. Cerebral hypothermia is not neuroprotective when started after postischemic seizures in fetal sheep. Pediatr Res. 1999; 46(3): 274-280. [PubMed: 10473041]

15. Smit E, Liu X, Jary S, Cowan F, Thoresen M. Cooling neonates who do not fulfil the standard cooling criteria: short- and long-term outcomes. Acta Paediatr. 2015; 104(2):138-145. [PubMed: 25164710]

16. Volpe, JJ. Neurology of the Newborn. 5th. Philadelphia, PA: Saunders Elsevier; 2008.

17. Ferriero DM. Neonatal brain injury. N Engl J Med. 2004; 351(19):1985-1995. [PubMed: 15525724]

18. Coimbra C, Wieloch T. Moderate hypothermia mitigates neuronal damage in the rat brain when initiated several hours following transient cerebral ischemia. Acta Neuropathol. 1994; 87(4):325331. [PubMed: 8017166]

19. Shankaran S, Laptook AR, McDonald SA, et al. Eunice Kennedy Shriver National Institute of Child Health and Human Development Neonatal Research Network. Temperature profile and outcomes of neonates undergoing whole body hypothermia for neonatal hypoxic-ischemic encephalopathy. Pediatr Crit Care Med. 2012; 13(1):53-59. [PubMed: 21499182]

20. Colbourne F, Corbett D. Delayed and prolonged post-ischemic hypothermia is neuroprotective in the gerbil. Brain Res. 1994; 654(2):265-272. [PubMed: 7987676]

21. Newman JE, Bann CM, Vohr BR, Dusick AM, Higgins RD, Follow-Up Study Group of Eunice Kennedy Shriver National Institute of Child Health and Human Development Neonatal Research Network. Improving the Neonatal Research Network annual certification for neurologic examination of the 18-22 month child. J Pediatr. 2012; 161(6):1041-1046. [PubMed: 22748517]

22. Bayley, N. Bayles Scales of Infant and Toddler Development. 3rd. San Antonio, TX: Harcourt Assessment; 2006. 
23. Palisano R, Rosenbaum P, Walter S, Russell D, Wood E, Galuppi B. Development and reliability of a system to classify gross motor function in children with cerebral palsy. Dev Med Child Neurol. 1997; 39(4):214-223. [PubMed: 9183258]

24. Lilford RJ, Thornton JG, Braunholtz D. Clinical trials and rare diseases: a way out of a conundrum. BMJ. 1995; 311(7020):1621-1625. [PubMed: 8555809]

25. Wijeysundera DN, Austin PC, Hux JE, Beattie WS, Laupacis A. Bayesian statistical inference enhances the interpretation of contemporary randomized controlled trials. J Clin Epidemiol. 2009; 62(1):13-21.e5. [PubMed: 18947971]

26. Pedroza C, Han W, Truong VT, Green C, Tyson JE. Performance of informative priors skeptical of large treatment effects in clinical trials: a simulation study [published online December 13, 2015]. Stat Methods Med Res.

27. Bracken MB. Why animal studies are often poor predictors of human reactions to exposure. J R Soc Med. 2009; 102(3):120-122. [PubMed: 19297654]

28. Spiegelhalter DJ, Myles JP, Jones DR, Abrams KR. Methods in health service research: an introduction to bayesian methods in health technology assessment. BMJ. 1999; 319(7208):508512. [PubMed: 10454409]

29. Rouse DJ, Hirtz DG, Thom E, et al. Eunice Kennedy Shriver NICHD Maternal-Fetal Medicine Units Network. A randomized, controlled trial of magnesium sulfate for the prevention of cerebral palsy. N Engl J Med. 2008; 359(9):895-905. [PubMed: 18753646]

30. Doyle LW, Crowther CA, Middleton P, Marret S, Rouse D. Magnesium sulphate for women at risk of preterm birth for neuroprotection of the fetus. Cochrane Database Syst Rev. 2009; (1):CD004661. [PubMed: 19160238]

31. Bibbins-Domingo K, Grossman DC, Curry SJ. US Preventive Services Task Force recommendation statement. JAMA. 2016; 316(19):1997-2007. [PubMed: 27838723]

32. Chou R, Dana T, Blazina I, Daeges M. Evidence Report and Systematic Review for the US Preventive Services Task Force. JAMA. 2016; 316(19):2008-2024. [PubMed: 27838722]

33. Jacobs SE, Berg M, Hunt R, Tarnow-Mordi WO, Inder TE, Davis PG. Cooling for newborns with hypoxic ischaemic encephalopathy. Cochrane Database Syst Rev. 2013; (1):CD003311. [PubMed: 23440789]

34. Li T, Xu F, Cheng X, et al. Systemic hypothermia induced within 10 hours after birth improved neurological outcome in newborns with hypoxic-ischemic encephalopathy. Hosp Pract (1995). 2009; 37(1):147-152. [PubMed: 20877184]

35. Azzopardi D, Strohm B, Linsell L, et al. UK TOBY Cooling Register. Implementation and conduct of therapeutic hypothermia for perinatal asphyxial encephalopathy in the UK: analysis of national data. PLoS One. 2012; 7(6):e38504. [PubMed: 22719897]

36. Shankaran S, Laptook AR, Pappas A, et al. Eunice Kennedy Shriver National Institute of Child Health and Human Development Neonatal Research Network. Effect of depth and a randomized clinical trial. JAMA. 2014; 312(24):2629-2639. [PubMed: 25536254]

37. Shankaran S, Laptook AR, Pappas A, et al. Eunice Kennedy Shriver National Institute of Child Health and Human Development Neonatal Research Network. Effect of depth and duration of cooling on death or disability at age 18 months among neonates with hypoxic-ischemic encephalopathy: a randomized clinical trial. JAMA. 2017; 318(1):57-67. [PubMed: 28672318]

38. Laptook A, Tyson J, Shankaran S, et al. National Institute of Child Health and Human Development Neonatal Research Network. Elevated temperature after hypoxic-ischemic encephalopathy: risk factor for adverse outcomes. Pediatrics. 2008; 122(3):491-499. [PubMed: 18762517]

39. Laptook AR, McDonald SA, Shankaran S, et al. Extended Hypothermia Follow-up Subcommittee of the National Institute of Child Health and Human Development Neonatal Research Network. Elevated temperature and 6-to 7-year outcome of neonatal encephalopathy. Ann Neurol. 2013; 73(4):520-528. [PubMed: 23595408]

40. Wyatt JS, Gluckman PD, Liu PY, et al. CoolCap Study Group. Determinants of outcomes after head cooling for neonatal encephalopathy. Pediatrics. 2007; 119(5):912-921. [PubMed: 17473091] 


\section{Key Points}

\section{Question}

Does initiation of hypothermia at 6 to 24 hours after birth reduce the risk of death or disability at 18 months among term newborns with hypoxic-ischemic encephalopathy?

\section{Findings}

In this Bayesian analysis of a randomized clinical trial of 168 newborns with hypoxicischemic encephalopathy, treatment with hypothermia initiated at 6 to 24 hours after birth compared with noncooling resulted in a $76 \%$ probability of any reduced death or disability, and a $64 \%$ probability of at least $2 \%$ less death or disability at 18 to 22 months.

\section{Meaning}

Hypothermia treatment initiated at 6 to 24 hours for newborns with hypoxic-ischemic encephalopathy may reduce death or disability but there is uncertainty in its effectiveness. 


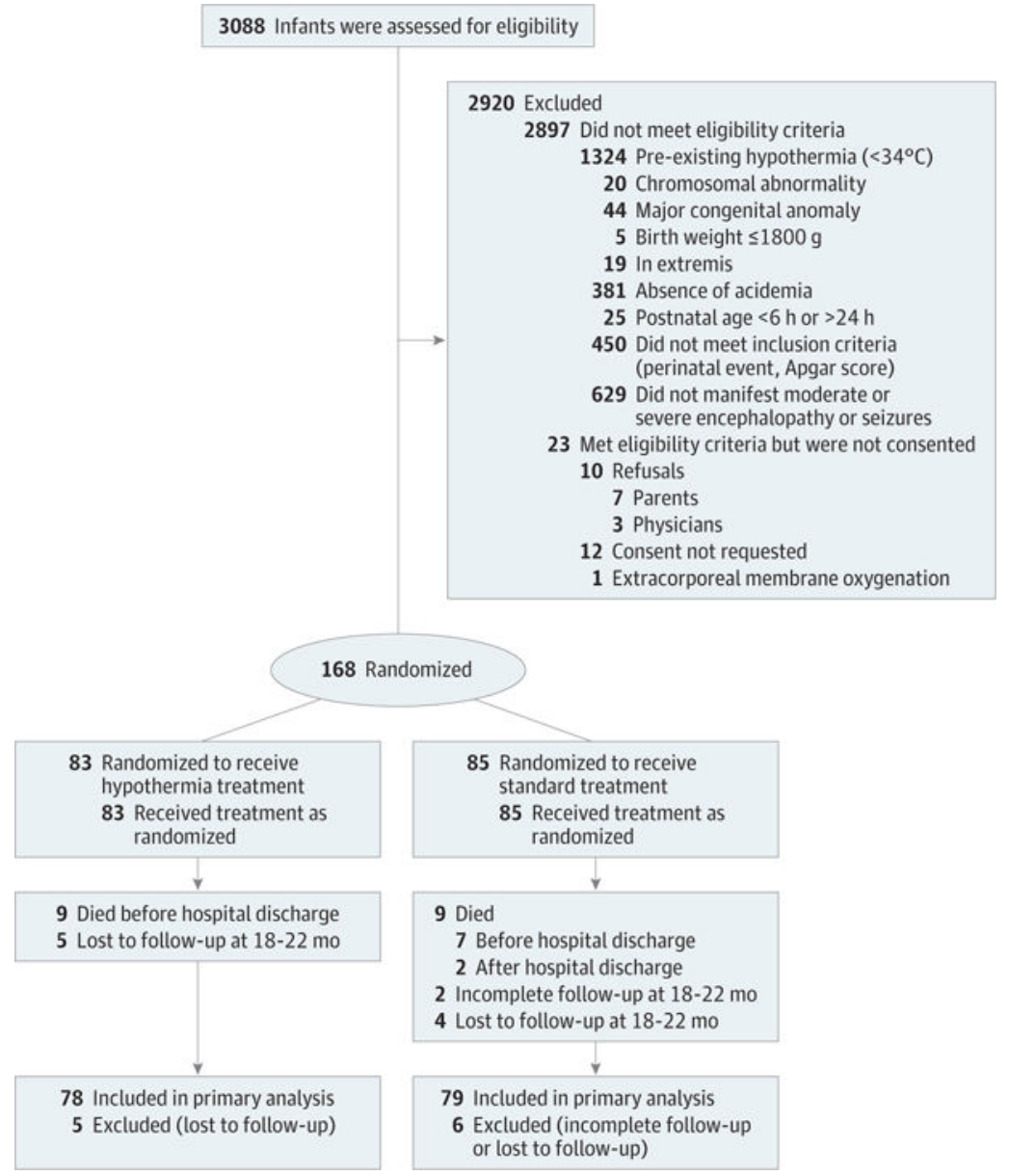

Figure 1.

Flow Diagram of Neonates With Hypoxic-Ischemic Encephalopathy Through a Trial of Hypothermia Initiated at 6 to 24 Hours After Birth 

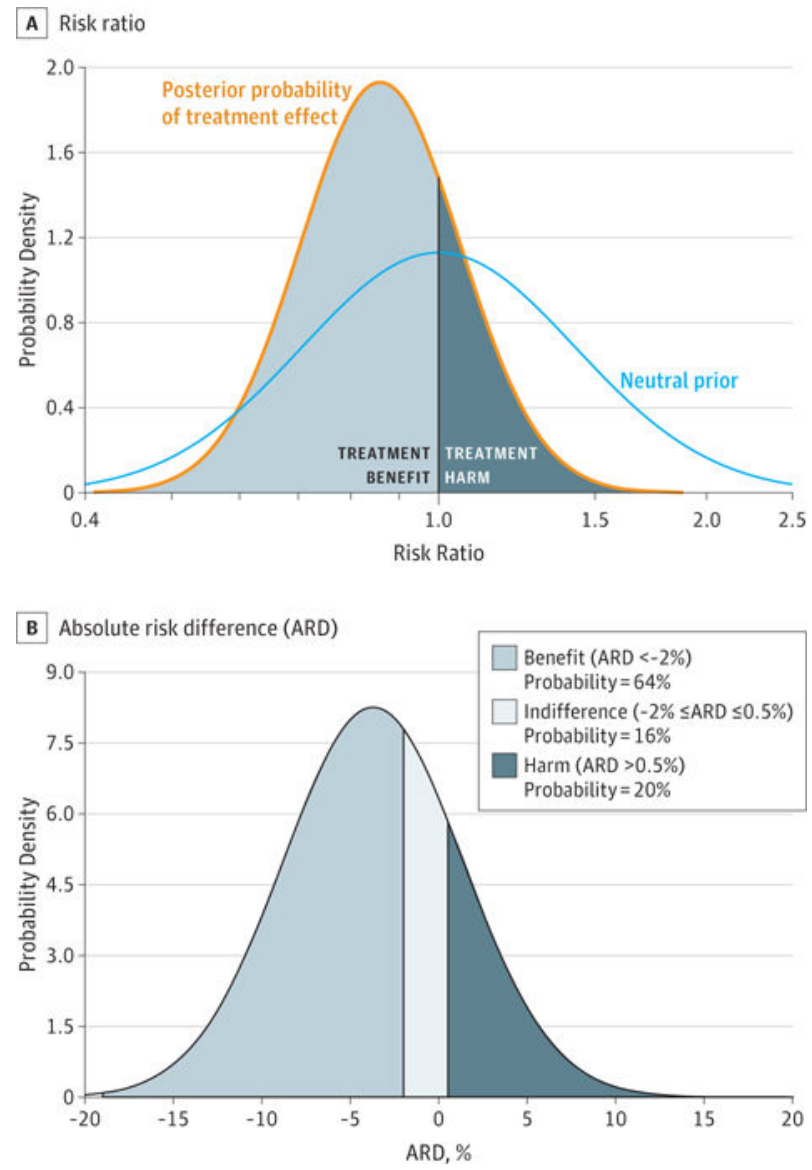

Figure 2. Posterior Probability of Death or Disability With Hypothermia Initiated at 6 to 24 Hours After Birth vs Noncooling

A, The probability density describes the frequency distribution of observed values and is unit-less. The curves are scaled so that the total area under the curve is 1 , and the area between any 2 values on the $x$-axis equals the probability of observing a value in that range. The blue line plots a neutral prior distribution centered at a risk ratio of 1.0 and indicates an equal number of infants would be expected to benefit by either temperature management group, hypothermia or noncooled. The posterior probability of treatment effect is derived by combining the prior distribution with the trial results. The distribution is shifted to the left of a risk ratio of 1.0 with a point estimate of 0.86 . The area under the curve that is less than a risk ratio of 1.0 (light blue) represents the posterior probability of any reduction in death or disability (76\% for this trial). The area under the curve that is greater than a risk ratio of 1.0 (dark blue) represents the posterior probability of an increase in death or disability (24\% for this trial). B, The light blue portion indicates a $64 \%$ probability that death or disability in infants treated with hypothermia is at least $2 \%$ less than noncooled infants (benefit). The pale blue area (near zero) is an arbitrary zone of indifference to illustrate the probability of risk differences where hypothermia and noncooling may be viewed as equivalent. The dark blue indicates the probability of death or disability among infants treated with hypothermia is higher than for noncooled infants (harm). In this example, a $2 \%$ absolute risk difference 
was associated with a 3.2-times $(64 \% / 20 \%)$ higher probability of reduced compared with increased death or disability risk among hypothermia relative to noncooled infants. 


\section{Table 1}

Maternal and Neonatal Characteristics ${ }^{a}$

\begin{tabular}{|c|c|c|}
\hline Characteristic & $\begin{array}{l}\text { Hypothermia Group } \\
(\mathbf{n}=\mathbf{8 3})\end{array}$ & $\begin{array}{l}\text { Noncooled Group } \\
(\mathbf{n}=\mathbf{8 5})\end{array}$ \\
\hline \multicolumn{3}{|l|}{ Maternal } \\
\hline Age, mean (SD), y & $27(6)$ & $26(6)$ \\
\hline Married, No. (\%) & $54(65)$ & $43(50.6)$ \\
\hline \multicolumn{3}{|l|}{ Race/ethnicity, No. (\%) } \\
\hline Black & $13(16.1)$ & $21(25)$ \\
\hline White & $61(75.3)$ & $60(71.4)$ \\
\hline Other $b$ & $7(8.6)$ & $3(3.6)$ \\
\hline Gravida, median (IQR) & $2(1-3)$ & $2(1.3)$ \\
\hline Parity, median (IQR) & $1(1-2)$ & $1(1-2)$ \\
\hline \multicolumn{3}{|l|}{ Education, No. $(\%)$} \\
\hline$\leq$ High school & $36(45.6)$ & $34(42.5)$ \\
\hline Any college or beyond & $43(54.4)$ & $46(57.5)$ \\
\hline \multicolumn{3}{|l|}{ Pregnancy complications, No. (\%) } \\
\hline Hypertension or pre-eclampsia & $13(15.7)$ & $17(20.2)$ \\
\hline Antepartum hemorrhage & $3(3.6)$ & $7(8.2)$ \\
\hline Thyroid dysfunction & $2(2.4)$ & $3(3.6)$ \\
\hline Diabetes & $7(8.4)$ & $9(10.7)$ \\
\hline \multicolumn{3}{|l|}{ Intrapartum complications, No. (\%) } \\
\hline Fetal decelerations & $59(72)$ & $60(70.6)$ \\
\hline Cord mishap (prolapse, rupture) & $9(10.8)$ & $13(15.3)$ \\
\hline Uterine rupture & $2(2.4)$ & $2(2.4)$ \\
\hline Maternal pyrexia $\left(\geq 37.6^{\circ} \mathrm{C}\right)$ & $10(12.1)$ & $9(10.8)$ \\
\hline Placental problems (abruptio, previa) & $9(10.8)$ & $10(11.8)$ \\
\hline Maternal trauma, CPR & $2(2.4)$ & $7(8.2)$ \\
\hline Shoulder dystocia & $8(9.8)$ & $4(4.7)$ \\
\hline Rupture of membranes, median (IQR), h & $3.2(0.02-11.9)$ & $5.5(0.03-15.5)$ \\
\hline Chorioamnionitis, clinical & $5(6.1)$ & $7(8.5)$ \\
\hline Chorioamnionitis, histologic, No./total No. $(\%)^{c}$ & $13 / 30(43.3)$ & $8 / 22(36.4)$ \\
\hline Emergency cesarean delivery & $47(56.6)$ & $52(61.2)$ \\
\hline \multicolumn{3}{|l|}{ Infant } \\
\hline Gestational age, mean (SD), wk & $39(2)$ & $39(1)$ \\
\hline Birth weight, mean (SD), g & $3379(528)$ & $3303(553)$ \\
\hline Length, mean (SD), cm & $51(3)$ & $51(3)$ \\
\hline Head circumference, mean (SD), cm & $34(2)$ & $34(2)$ \\
\hline Male, No. (\%) & $47(56.6)$ & $55(64.7)$ \\
\hline Transferred to treating center, No. (\%) & $71(85.5)$ & $75(88.2)$ \\
\hline
\end{tabular}




\begin{tabular}{|c|c|c|}
\hline Characteristic & $\begin{array}{l}\text { Hypothermia Group } \\
(\mathbf{n}=\mathbf{8 3})\end{array}$ & $\begin{array}{l}\text { Noncooled Group } \\
(\mathbf{n}=\mathbf{8 5})\end{array}$ \\
\hline \multicolumn{3}{|l|}{ Delivery room, No. (\%) } \\
\hline Intubation & $47(58.0)$ & $45(52.9)$ \\
\hline Chest compressions & $19(23.5)$ & $25(29.4)$ \\
\hline Medication & $9(11.1)$ & $11(12.9)$ \\
\hline Time to spontaneous respirations $>10 \mathrm{~min}$ & $24(30.0)$ & $34(41.0)$ \\
\hline \multicolumn{3}{|l|}{ Apgar score <5, No. (\%) } \\
\hline At $5 \mathrm{~min}$ & $42(50.6)$ & $43(50.6)$ \\
\hline At $10 \min ^{d}$ & $18(28.6)$ & $20(26.0)$ \\
\hline \multicolumn{3}{|l|}{ Cord blood, mean (SD) } \\
\hline $\mathrm{pH}$ & $6.96(0.16)$ & $6.99(0.16)$ \\
\hline Base deficit & $14.8(5.8)$ & $13.9(5.3)$ \\
\hline \multicolumn{3}{|l|}{ At randomization } \\
\hline Age, mean (SD), h & $16(5)$ & $15(5)$ \\
\hline$\Varangle 6$ to $\leq 2 \mathrm{~h}$, No. $(\%)$ & $26(31.3)$ & $28(32.9)$ \\
\hline$>12$ to $24 \mathrm{~h}$, No. (\%) & $57(68.7)$ & $57(67.1)$ \\
\hline \multicolumn{3}{|l|}{ Level of encephalopathy, No. (\%) } \\
\hline Moderate encephalopathy & $73(88.0)$ & $78(91.8)$ \\
\hline Severe encephalopathy & $10(12.1)$ & $7(8.2)$ \\
\hline Clinical seizures at randomization, No. (\%) & $63(75.9)$ & $56(65.9)$ \\
\hline Anticonvulsants at randomization, No. (\%) & $56(72.7)$ & $48(67.1)$ \\
\hline Inotropic support at randomization, No. (\%) & $17(21.0)$ & $16(18.8)$ \\
\hline
\end{tabular}

Abbreviations: CPR, cardiopulmonary resuscitation; IQR, interquartile range.

${ }^{a}$ Percentages are based on the number of mothers and infants for whom data were available. Missing data: maternal education ( 9 missing), race/ ethnicity ( 3 missing), rupture of membrane ( 8 missing), hypertension/pre-eclampsia (1 missing), fetal decelerations (1 missing), cord mishap (1 missing), fetal decelerations ( 2 missing), shoulder dystocia (1 missing), length ( 2 missing), head circumference ( 3 missing), intubation ( 2 missing), chest compression ( 2 missing), medication ( 2 missing), time to spontaneous respiration (5 missing), Apgar score at $10 \mathrm{~min}$ (79 missing), $\mathrm{pH}$ (42 missing), base deficit (65 missing), anticonvulsants at randomization (21 missing), and inotropic support at randomization (3 missing).

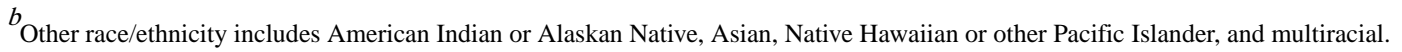

${ }^{c}$ Percentage based on the number of mothers with placental pathology performed $(n=30$ in the hypothermia group and $n=22$ in the noncooled group).

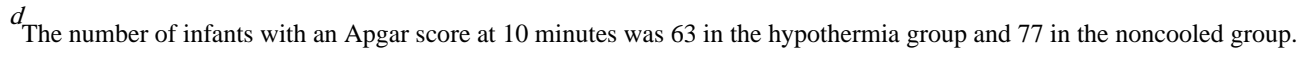




\section{Table 2}

Neonatal Adverse Events and Hospital Outcomes ${ }^{a}$

\begin{tabular}{|c|c|c|c|c|}
\hline \multirow[b]{2}{*}{ Event or Outcome } & \multicolumn{2}{|l|}{ No. $(\%)$} & \multirow[b]{2}{*}{$P$ Value } & \multirow[b]{2}{*}{$\begin{array}{l}\text { Absolute Differences } \\
\text { (95\% CI) }\end{array}$} \\
\hline & $\begin{array}{l}\text { Hypothermia } \\
(\mathbf{n}=\mathbf{8 3})\end{array}$ & $\begin{array}{l}\text { Noncooled } \\
(\mathbf{n}=\mathbf{8 5})\end{array}$ & & \\
\hline \multicolumn{5}{|l|}{ Adverse Events $b$} \\
\hline Arrhythmia needing treatment & 0 & 0 & & \\
\hline Persistent metabolic acidosis & 0 & 0 & & \\
\hline Thrombosis & 0 & 0 & & \\
\hline Bleeding & $4(4.8)$ & $1(1.2)$ & .21 & $0.04(-0.02$ to 0.09$)$ \\
\hline Altered skin integrity & $1(1.2)$ & $0(0)$ & & $0.01(-0.01$ to 0.04$)$ \\
\hline Death & $6(7.2)$ & $5(5.9)$ & .76 & $0.01(-0.06$ to 0.09$)$ \\
\hline Other $^{c}$ & $2(2.4)$ & 0 & & $0.02(-0.01$ to 0.06$)$ \\
\hline \multicolumn{5}{|l|}{ Neonatal Outcomes in the Hospital } \\
\hline Meconium aspiration syndrome & $23(27.7)$ & $20(23.5)$ & .60 & $0.04(-0.09$ to 0.17$)$ \\
\hline Pulmonary artery hypertension & $20(24.1)$ & $13(15.3)$ & .18 & $0.09(-0.03$ to 0.21$)$ \\
\hline Inhaled nitric oxide use & $14(16.9)$ & $15(17.7)$ & $>.99$ & $0.01(-0.11$ to 0.12$)$ \\
\hline ECMO & $3(3.6)$ & $2(2.4)$ & .68 & $0.01(-0.04$ to 0.06$)$ \\
\hline Ventilation during 96-h intervention & $49(59.0)$ & $44(51.8)$ & .34 & $0.07(-0.08$ to 0.22$)$ \\
\hline Cardiac ischemia $d$ & $14(16.9)$ & $13(15.5)$ & .84 & $0.02(-0.1$ to 0.13$)$ \\
\hline Hypotension treated with vasopressors & $28(33.7)$ & $24(28.2)$ & .51 & $0.05(-0.08$ to 0.19$)$ \\
\hline Oliguria & $19(23.0)$ & $18(21.2)$ & .85 & $0.02(-0.11$ to 0.14$)$ \\
\hline Hepatic dysfunction & $19(22.9)$ & $24(28.2)$ & .48 & $0.05(-0.08$ to 0.19$)$ \\
\hline Disseminated intravascular coagulation & $9(10.8)$ & $4(4.7)$ & .16 & $0.06(-0.02$ to 0.14$)$ \\
\hline Bacteremia & $2(2.4)$ & $1(1.2)$ & .62 & $0.01(-0.03$ to 0.05$)$ \\
\hline Clinical seizures (any time) & $64(77.1)$ & $64(75.3)$ & .86 & $0.02(-0.11$ to 0.15$)$ \\
\hline EEG recording & $69(83.1)$ & $70(82.4)$ & $>.99$ & $0.01(-0.11$ to 0.12$)$ \\
\hline Electrographic seizures ${ }^{e}$ & $26(37.7)$ & $25(34.7)$ & .86 & $0.02(-0.14$ to 0.18$)$ \\
\hline Abnormal EEG background ${ }^{e}$ & $49(71.0)$ & $48(68.6)$ & .85 & $0.02(-0.13$ to 0.18$)$ \\
\hline Glucose concentration $<40 \mathrm{mg} / \mathrm{dL}$ & $5(6.0)$ & $6(7.1)$ & $>.99$ & $0.01(-0.06$ to 0.09$)$ \\
\hline Glucose concentration $>150 \mathrm{mg} / \mathrm{dL}$ & $33(39.8)$ & $14(16.7)$ & .001 & 0.23 (0.1 to 0.36$)$ \\
\hline Analgesics during 96-h intervention & $41(50.0)$ & $30(35.6)$ & .055 & 0.15 (0.0 to 0.30$)$ \\
\hline DNR order & $7(8.4)$ & $8(9.4)$ & $>.99$ & $0.01(-0.08$ to 0.1$)$ \\
\hline DNR order and support withdrawn & $6(7.2)$ & $8(9.4)$ & .47 & $0.02(-0.06$ to 0.11$)$ \\
\hline Gastrostomy tube or gavage feed at discharge & $1(1.4)$ & $1(1.3)$ & $>.99$ & $0(-0.03$ to 0.03$)$ \\
\hline Death prior to discharge & $9(10.8)$ & $7(8.2)$ & .61 & $0.04(-0.09$ to 0.17$)$ \\
\hline
\end{tabular}

Abbreviations: DNR, do not resuscitate; ECMO, extracorporeal membrane oxygenation; EEG, electroencephalogram.

SI conversion factor: To convert glucose to millimoles per liter, multiply by 0.0555 . 
${ }^{a}$ Percentages are based on the number of infants for whom data were available. Hospital outcomes reflect the number of infants experiencing the outcome. Multiple adverse events occurred in 3 hypothermic infants and 1 control infant.

${ }^{b}$ Adverse events during the 96-h intervention and the interval of rewarming.

${ }^{c}$ Other indicates adverse events not prespecified. This was persistent pulmonary artery hypertension with induction of hypothermia in one infant and during hypothermia in a second infant.

${ }^{d}$ Cardiac ischemia was defined as elevation of cardiac enzymes or troponin or electrocardiographic changes

Denominator is the number of infants who had an EEG recording. 


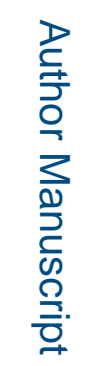

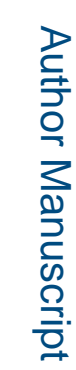

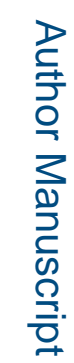

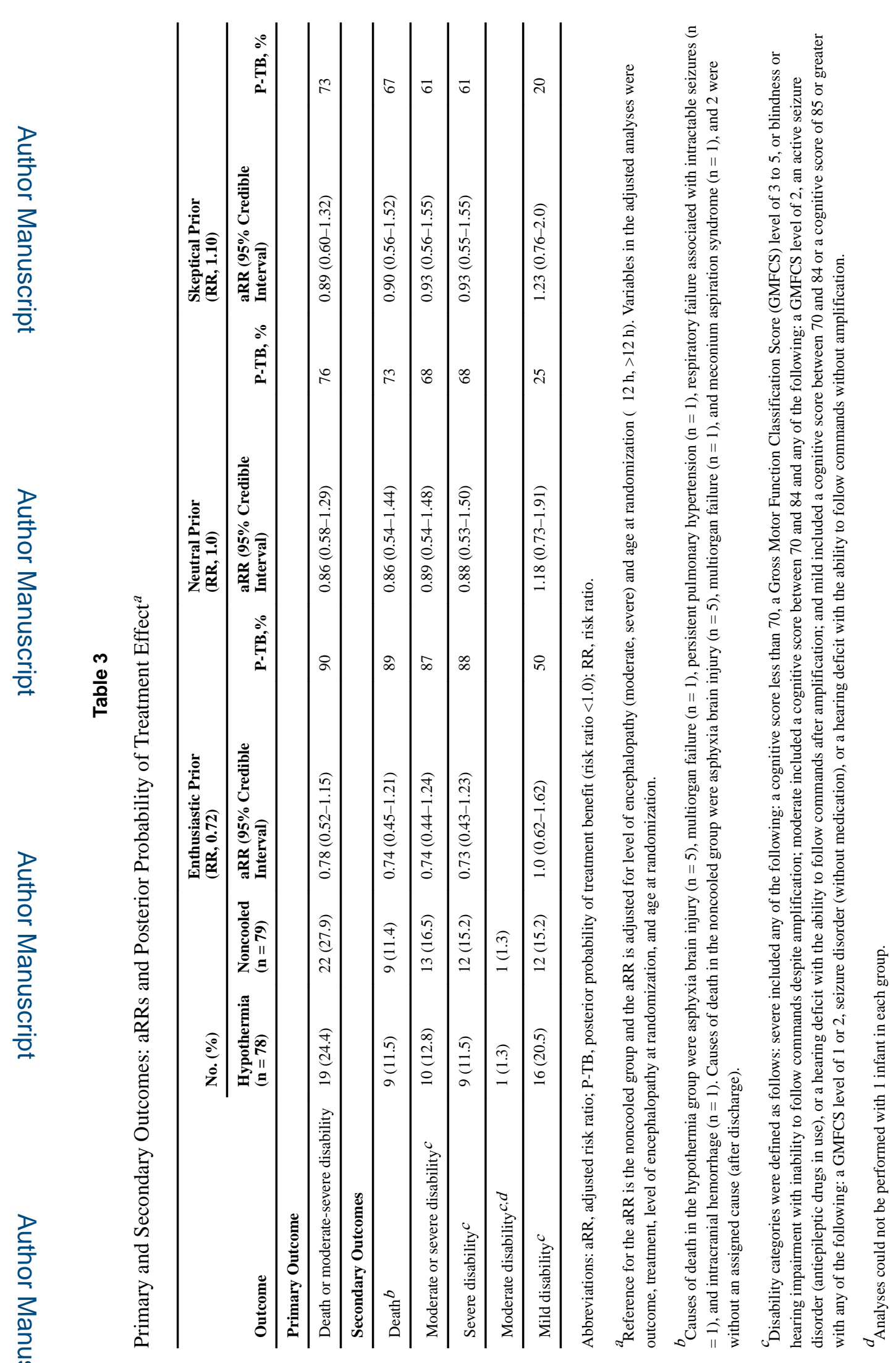

JAMA. Author manuscript; available in PMC 2018 January 24. 